\title{
TCF FEDERAL: JURIDIFICACIÓN DE LA POLÍTICA - POLITIZACIÓN DE LA JUSTICIA
}

Profesora. Dra. Evelyn HaAs Ex Magistrado de la Corte Constitucional Alemana

Si nos basamos en la comprensión dominante en Alemania sobre el Estado de Derecho y la predominancia de la Constitución, entonces la juridificación de la política, la necesidad de circunscribir normativamente la acción política, deriva obligadamente en su judicialización. Los proyectos políticos del gobierno legitimado democráticamente son justiciables y entregados al control jurídico de los jueces del Tribunal Constitucional Federal (TCF). En la actualidad no se discute la competencia de los tribunales constitucionales para derogar las leyes aprobadas por el legislador democráticamente legitimado, hecho que fue muy controvertido a inicios del siglo XX en la ciencia del Derecho del Estado, que además está regulada en el derecho constitucional. Con esto, en mayor o menor medida, se le otorgan poderes para configurar la política e influir en ella. La pregunta sobre si se puede hablar por ello de una politización de los magistrados del TCF deberá ser contestada con reserva.

Es por todos sabido que el TCF ostenta una posición importante en la vida política de Alemania, siendo acusado a veces de ser un gobierno paralelo e incluso de contrapoder.

\section{¿CÓMO SE HA LLEGAdO A ESTA APRECIACIÓN?}

El TCF es un órgano constitucional como el Presidente federal o el Gobierno federal. Su existencia, al igual que sus funciones y tareas, están normadas en la Constitución de modo que participa en la dirección superior del Estado, y el Estado alemán recibe de allí su conformación específica, especialmente en lo referido a la división de poderes. Sin embargo, esto por sí sólo no explica la fuerte posición que ostenta el TCF.

Debe haber algo más:

Y lo hay en los hechos. Es justamente el cúmulo de atribuciones y competencia que los padres de la Constitución le asignaron al TCF, como custodio de la Constitución, lo que le permite a éste una participación decisiva en la conducción 
política del Estado. Quien ostenta el control sobre la Constitución, que es derecho político, ejerce un alto grado de poder político.

El TCF influye y dirige la acción del Estado a través del conocimiento jurídico ganado en el proceso de descubrir el derecho. Las normas de la Constitución, demasiado generales y faltas de contenido, dejan mucho margen a la creatividad de los jueces del tribunal. Así, por ejemplo, también han sido modificados conceptos tradicionales como el de la familia. En el derecho alemán, y tal como se entiende en el lenguaje común, la familia siempre se comprendió como una comunidad de padre, madre e hijos unida por un vínculo jurídico. Conforme a la Constitución, esta comunidad goza de la protección especial del Estado. El TCF ha modificado el significado del concepto de familia cuando lo aplica a cualquier convivencia de varias personas sin vínculo jurídico, como ha sucedido en la jurisdicción reciente. Con ello, ahora la política debe otorgar la protección especial de la Constitución (artículo 60 de la Ley Fundamental), mucho más allá de lo deseado originalmente por el poder constituyente, también a aquellas comunidades de personas que no tienen permanencia ni solidez debido a la falta de un vínculo jurídico o biológico.

En el pasado, el TCF además ha sabido ampliar continuamente sus competencias sin alterarlas formalmente. A continuación abordaremos este aspecto.

1. El poder, la ambición de dominio y el ejercicio del mismo en el Estado, nunca ha sido la formulación de políticas de carácter independiente. En el mundo de hoy, marcado por una economía globalizada, quizá menos antes.

Bajo la influencia de las doctrinas de los filósofos griegos, desde la antigüedad y a lo largo de muchos siglos, fue communis opinio que la ética debía disciplinar el contenido de la política, como parte de ésta. El poder ejercido bajo este principio no corre peligro de caer en el abuso o la arbitrariedad.

Sin embargo, esta vinculación de la ética a la política se ha ido perdiendo con el correr de la historia. Con esto no quiero decir que en todas las épocas cada gobierno y orden social se haya sentido comprometido con el ideal político griego (tiranía griega, condotieros del Renacimiento), pero esta dependencia se pierde a más tardar a partir del siglo XVIII.

Esto no significa que la política de los monarcas que gobernaban con poder absoluto no estuviera sujeta a ninguna obligación, sin embargo, ésta carecía de la referencia ética y de la consecuente disciplinización del poder. Tal tipo de poder sin límites es susceptible de caer en el abuso y la arbitrariedad.

No obstante, también es cierto que en estos siglos no dominaron siempre los gobiernos sin contención. Por ejemplo, sabemos que Federico el Grande 
consideraba las leyes como vinculantes también para sí mismo. Otros monarcas que actuaban con responsabilidad adherían a los principios de asistencia social y el bienestar de sus súbditos. Ejemplos elocuentes de esto son los "espejos de los príncipes" y las "ordenanzas policiales".

El Estado moderno busca compensar este déficit, pero ya no busca su salvación en la vinculación de la política a la ética: en lugar de la ética, ahora es la constitución "escrita" la que debe poner límites al poder del Estado y disciplinarlo.

2. El Estado constitucionalizado de la Modernidad amarra al poder en un sistema normativo que, como ordenamiento marco u ordenamiento reglamentario, puede ser dotado de normas vinculantes o no vinculantes, es decir, de propósitos directamente vinculantes para el poder del Estado. Respecto de su vinculatoriedad, el derecho constitucional tiene primacía frente al derecho (corriente), es decir, las leyes, decretos, resoluciones y reglamentos. Una política orientada por los principios constitucionales del Estado Social y de Derecho atraviesa prácticamente todas las esferas de la comunidad.

La política dicta normas jurídicas y se encuentra ella misma bajo la curatela del derecho, del Derecho Constitucional. El marco trazado por la Constitución le fija a la política los límites que debe respetar en su acción. Esto implica beneficios para cada uno de los ciudadanos, como la previsibilidad de la acción del Estado, la protección de la confianza legítima, entre otras. Sin embargo, estos beneficios pueden convertirse en perjuicios para la comunidad estatal.

3. La política vinculada jurídicamente pierde su ductibilidad y flexibilidad, su espontaneidad, la capacidad de reaccionar rápidamente a situaciones de la vida en permanente cambio. Una política atada al derecho constitucional no sólo se somete a mayores límites, con las decisiones de los tribunales constitucionales, además debe asumir una cierta provisionalidad de sus decisiones, justo de aquéllas, especialmente importantes, eminentemente políticas, pues, siendo la política el gobierno de la sociedad sobre la base de la posesión del poder, entonces se ve mermada con esto.

El poder que le corresponde a los tribunales constitucionales depende, no en última instancia, de la estructura, es decir, de la organización y composición de la magistratura, así como de las competencias, del derecho a la justicia y del efecto jurídico y fáctico de sus decisiones, es decir, de la aceptación de las decisiones por parte de la población y de los responsables políticos.

Mientras más competencias tenga un tribunal constitucional, mientras mayor sea su posibilidad de involucrarse intensamente en la vida política del Estado, más oportunidades tendrá de ofrecer un contrapeso a la política, cuestionar su autoridad y, en cambio, fortalecer la propia. 
El poder que puede ejercer un tribunal constitucional depende también del grado de constitucionalización, de la validez directamente y vinculante de las normas constitucionales. Las declaraciones programáticas y directrices pueden señalar objetivos a la política, sin embargo, no la limitan. Aquellas constituciones que, como la alemana, presentan un alto grado de regulación, entregan una sólida base a la jurisdicción constitucional.

4. Al TCF le corresponde la prerrogativa de interpretación de la Constitución. Como legítimo intérprete de la Constitución determina el contenido de la misma. Su interpretación y su resolución, su veredicto, para lo que necesita 5 de los 8 votos de los jueces, marchita la concreción de los sueños políticos, que tampoco pueden reanimarse muy rápido, puesto que la decisión del TCF tiene un efecto ilimitado en el tiempo, lo que le impide al legislador esquivar el veredicto con una nueva ley del mismo tenor.

Los tribunales constitucionales poseen una doble naturaleza. Hans Kelsen advirtió en su momento que la anulación de una ley tiene ella misma carácter legislativo, es decir, es legislación negativa. La anulación de leyes crea una nueva situación jurídica. Esto sucede al mismo tiempo con mecanismos propios del poder judicial, es decir, mediante la aplicación del derecho y en una organización de tipo judicial, de forma que se puede hablar con razón del TCF como un tribunal.

Por ello es absolutamente lógico que el legislador alemán le asigne fuerza de ley a las resoluciones del TCF en determinados procesos. Estos fallos son publicados como leyes en el Diario Oficial, no en su totalidad pero sí en su tenor.

5. El talón de Aquiles de la jurisdicción constitucional es que carece de cualquier posibilidad de sanción. No puede imponer sus decisiones, pues no dispone del instrumental para ello y, en consecuencia, depende de la disposición y voluntad de cooperación de la misma política a la que ha reprendido. Esto sucede especialmente cuando el poder político enfrenta una situación en que piensa que no puede aventurarse a una confrontación con el TCF.

El ejemplo alemán muestra que el gran aprecio de que goza el TCF entre la población genera tal tipo de situación. Esto se ve favorecido principalmente por los medios de comunicación, que prodigan comentarios elogiosos incluso cuando se trata de fallos errados del tribunal, lo que naturalmente también sucede. Medios de comunicación que vigilan, muchas veces con rigor y acuciados por las partes interesadas, si el poder político implementa las normas del TCF y cómo lo hace, especialmente cuando se trata de decisiones con impacto en la opinión pública.

El gran aprecio de que goza el TFC entre la población no se explica, o por lo menos no predominante, porque haya guiado sus decisiones aplicando un justo sentido de las proporciones, sino, en mi opinión, ante todo por la historia, por los 
sucesos históricos del último siglo, que han sentado condiciones muy especiales para ello, así como por la cultura fuertemente legalista de nuestro país.

1. Alemania no es sólo un Estado constitucional, se podría decir que es una sociedad constitucional. Se habla acertadamente del patriotismo constitucional de los alemanes; un estado emocional que se irradia benévolamente sobre los custodios de esta Constitución.

En esta Constitución de 1949, la nación encontró el resarcimiento a los valores extraviados después de dos guerras perdidas, que además no cargaba con los hechos del pasado y auguraba un futuro prometedor. En este proceso emprendido por la sociedad para descubrir su identidad durante los primeros años de la República de Bonn, el TCF le otorgó a la Constitución una eficiencia insospechada, mucho más allá de la medida intencionada por el legislador. Hasta nuestros días ha trascendido la afirmación del primer Jefe de Gobierno de Alemania, Konrad Adenauer, quien participó liderando la elaboración de la Constitución: "no la habíamos imaginado así”. Otros comentarios similares y aún más drásticos han acompañado a la jurisdicción del TCF a lo largo de las décadas.

2. En los hechos, el TCF no sólo ha agotado consecuente las múltiples competencias que le otorgó el legislador, sino las ha seguido ampliando en su contenido durante las últimas décadas, incorporando otros ámbitos jurisdiccionales. Esto ha llevado naturalmente a que se haya trastrocado el equilibrio entre los poderes del Estado en nuestro Estado democrático con su separación de poderes. No obstante, no creo que se pueda hablar aún de una supremacía del TCF frente a los otros poderes del Estado.

La razón de esto no debería buscarse en que el TCF no puede tomar la iniciativa ni iniciar un proceso legislativo, a lo que siempre se hace referencia en este contexto; tampoco puede inmiscuirse a voluntad en los procesos de decisión política y atraer así un proceso. Como también es conveniente ser reservados en las declaraciones públicas. Si bien es cierto que el tribunal sólo pueda controlar las leyes aprobadas por el parlamento y la aplicación de las mismas en la vida real por parte de las autoridades públicas y tribunales cuando se le solicita, no es realmente convincente la remisión a la falta de iniciativa legislativa, pues en el pasado prácticamente no ha existido ninguna ley de alguna importancia política que no se haya presentado al TCF para su control.

En el marco de la adopción de sus decisiones, el tribunal agota los recursos argumentativos y le indica a la política una situación jurídica de conformidad con la Constitución. Este efecto no deber ser subestimado. Acto seguido, el legislador 
parlamentario adopta de buen grado las indicaciones y reformula la ley de acuerdo con las indicaciones del TCF, incluso en aquellos casos en que dispone de un buen grado de discrecionalidad. Esto tiene sus causas. Una de ellas es seguramente que la política puede remitirse a la decisión del TCF cuando se trata de medidas impopulares. Otro motivo no menor es que la enmienda de una situación jurídica ya vigente, por parte de una resolución judicial, adquiere una importancia mucho más decisiva, en lo referido al impacto externo, que una opinión consultiva del TCF, emitida antes de decretar una ley, impide la promulgación de leyes inconstitucionales. Ningún gobierno puede permitirse a la larga ser acusado repetidamente de una acción inconstitucional. Con la anulación de sus leyes no sólo pierde los instrumentos para su acción política, además arriesga perder su credibilidad ante la población.

III

Algunos ejemplos permiten ilustrar cómo ha influido el TCF, haciendo uso de su prerrogativa de interpretación de la Constitución, en la juridificación de la política y cómo ha intervenido en la conformación del proceso político.

1. Desde que se promulgó la Ley Fundamental, la opinión dominante en la literatura jurídica ha sido que los derechos fundamentales, como el derecho de propiedad, la libertad de culto, para nombrar sólo dos, fueron concebidos como derechos de defensa de las libertades del individuo frente al Estado. Según esto, no tienen relevancia para las relaciones de Derecho Civil de los ciudadanos entre sí, faltando la llamada eficacia frente a terceros.

El TCF tampoco lo ha enfrentado en su jurisdicción. Sin embargo, tempranamente le quitó importancia al debate sobre la eficacia frente a terceros en los derechos fundamentales en el ámbito del Derecho Civil. En tanto reconoció los derechos fundamentales como un sistema objetivo de valores, las controversias jurídicas en las relaciones jurídicas del derecho civil, al igual que las leyes relativas al derecho civil, debían ser conocidas por los tribunales civiles podían ser controlados a tal efecto por el TCF. Con ello, el extenso ámbito del Derecho civil estaba sujeto también a la jurisdicción del TCF.

2. ¡Pero no era suficiente! El TCF fecundó además en otro sentido su tesis de que los derechos fundamentales representan un sistema objetivo de valores, con la consecuencia de que extendió simultáneamente su poder jurisdiccional y su esfera de influencia en una medida considerable.

El TCF, en una serie de decisiones y en virtud de su prerrogativa de interpretación, origina deberes de protección del Estado a partir de los derechos fundamentales concebidos como derechos de defensa frente al Estado. Protección que, 
conforme a la Constitución, pueden exigir los ciudadanos al Estado cuando se ven confrontados entre sí. Según esto, los derechos de libertad protegen no sólo al individuo ante intromisiones de los poderes del Estado en su esfera de libertad, sino obligan también al Estado a proteger esta esfera de libertad.

Este deber de protección debe ser cumplido en primera línea por el legislador. El TCF se toma el derecho, naturalmente sólo cuando se lo solicitan, de controlar si el poder político ha cumplido también con este deber escogido por él de entre las normas constitucionales y, con ello, estatuido como vinculante para el poder político. Hasta ahora interviene sólo cuando, en su apreciación, resulta evidente que no se ha cumplido. Según la jurisdicción actual, aún moderada, el tribunal establece que existe una omisión inconstitucional del poder político sólo cuando no se ha adoptado ninguna medida material de protección, o las adoptadas han sido insuficientes para alcanzar el objetivo de proteger.

A partir de los argumentos de la decisión, el poder político puede desprender qué acciones habrían sido necesarias para satisfacer el deber de protección conforme al derecho constitucional. En estos casos el TCF interviene trazando él mismo e indicándole al poder político las líneas gruesas de acción.

3. En este contexto, y como otro ejemplo, se debe observar la reserva legal de las intervenciones del Estado en la esfera de los ciudadanos, completamente perfeccionada por el TCF, que comprende todas las intervenciones independientemente de su gravedad e intensidad. Así, incluso la imposición de una multa de 5 euros exige una base normativa. El TCF se remite al principio del Estado de derecho para entregar su opinión jurídica.

El TCF exige además que la ley vele por el principio de proporcionalidad, lo que debe ser considerado siempre por el legislador en el diseño de las leyes. El TCF controla detalladamente la observancia de este principio que, normado en otros tiempos en las ordenanzas de policía como derecho positivo, fue revalorizado por el TCF como un principio no escrito con rango constitucional en el marco de la revisión de constitucionalidad. Y esto tiene su causa: aquí se abren insospechados espacios de conformación para el TCF.

En los inicios de su jurisdicción, el tribunal se contentaba con establecer si el legislador había considerado el momento de la proporcionalidad, pero muy pronto procedió a evaluar la proporcionalidad misma en base a criterios específicos como su idoneidad, necesidad y proporcionalidad en sentido más estricto.

Estos criterios son muy amplios. En particular el criterio de proporcionalidad, de proporcionalidad en sentido estricto, no se puede concebir metodológica y dogmáticamente y sólo puede abordarse desde una perspectiva decisionista. En consecuencia, ya no se puede hablar de aplicación del derecho. Por ello, durante 
décadas la jurisdicción ha enfrentado con razón la dura crítica de la doctrina del derecho político alemán. Renombrados catedráticos de la teoría del Estado han hablado de una "fórmula mágica" que debe ser observada con recelo.

El TCF ha permanecido imperturbable. Son evidentes los beneficios que su jurisdicción aportan al tribunal y éste no desea prescindir de ellos. La ponderación y los criterios aplicados posibilitan al tribunal disimular a voluntad las decisiones del poder político y anteponer sus propias apreciaciones, también políticas, en la ponderación de todos los hechos que conoce, en el lugar del legislador.

4. Otro rol juega la llamada reserva democrática de limitación legal postulada por el TCF. Según ésta, la acción del Estado debe ser regulada siempre mediante ley formal en tanto sean afectados los derechos fundamentales de los ciudadanos. Aquí, el tribunal reconoce incluso que no cabe deducir un deber expreso de normar de la constitución (BVerfGE 40,248) e infiere la exigencia simplemente del sometimiento del juez a la ley (art. 20 III Ley Fundamental).

Aclarando, la fórmula es la siguiente: el parlamento debe promulgar una ley cuando el objeto de regulación sea "esencial para la realización de los derechos fundamentales".

La fórmula es confusa y, como era de esperar, en los legisladores confundidos desencadenó un dinamismo legislativo, con la consecuente oleada de leyes.

En 1928, el catedrático en teoría del Estado, Hermann Heller, formuló respecto del objeto de la reserva de ley: "eso no lo determina la lógica ni una fórmula teórica, sino la tradición, conveniencia, correlación de fuerzas y conciencia jurídica", pero actualmente es más fácil. El TCF, al que le corresponde la última decisión, es quien determina qué es esencial, es decir, si una ley debe o no debe ser promulgada.

5. Los derechos fundamentales han sido definidos en forma concisa en la Constitución y muchas veces se circunscriben a una oración. El TCF ha visto su función en perfeccionar el fondo de los derechos fundamentales y ampliar de esta forma su contenido. Así, en el transcurso del tiempo, una oración ha derivado en un completo sistema. En este sentido, podemos mencionar el derecho de acceso a la radiodifusión y la libertad de prensa. El derecho al libre desarrollo de la personalidad derivó en un derecho a la libertad de acción y posteriormente también en un derecho a la protección de los datos. Este último adquirió importancia no en último lugar porque el TCF oponiéndose en varios procesos individuales (recopilación, almacenamiento, transmisión, eliminación de los datos) lo que hasta entones era un proceso administrativo único y separado. Con esto, para el legislador se multiplicó el peligro de regular la materia de forma inconstitucional. Se multiplicaron también las leyes consideradas como necesarias por el tribunal, que debieron ser presentadas nuevamente al TCF para su revisión. Sus decisiones 
dirigieron y dirigen "en cada detalle" el proceso parlamentario de regulación. Resulta un esfuerzo inútil buscar en la Constitución los criterios usados por el TCF para sus controles.

Parece confirmarse con posterioridad de la forma más acertada la crítica del catedrático alemán en derecho público, Carl Schmidt, a la vaguedad de contenido de las normas constitucionales, en especial de los derechos fundamentales, y su inquietud que desembocó en rechazo.

Ernst Forsthoff -un catedrático alemán en derecho público también- hace suya la crítica de Schmidt a la Constitución y al Tribunal Constitucional "un huevo cósmico jurídico", del que todo surge, desde el Código Penal hasta la ley que regula la fabricación de termómetros.

6. Para terminar, algunas palabras sobre la interpretación de las leyes conforme a la Constitución practicada por el TCF. Una norma identificada como inconstitucional no es declarada nula o como incompatible con la Constitución por el tribunal, si no es interpretada conforme a la Constitución, lo que sucede otorgándole otro contenido posible, que reciba la consagración de la constitucionalidad. El TCF proporciona vigencia legal a la norma con este contenido en el ordenamiento jurídico. Esta forma de proceder encuentra sus límites en el hecho de que la interpretación no puede contradecir la voluntad explícita del legislador, tal como ésta se manifiesta en los materiales.

Naturalmente el legislador es libre de anular acto seguido la norma o de enmendarla. Sin embargo, en principio y hasta nuevo aviso rige la situación jurídica sólo en el sentido determinado por el TCF. Y eso puede durar un buen rato, pues, por un lado la participación de varios partidos en el gobierno enlentece el proceso de decisión en su seno y, por el otro, porque el proceso legislativo mismo nunca ha sido ágil, para no caracterizarlo también de lento.

7. El TCF también puede expresar su voluntad de conformación dictando regulaciones transitorias. El tribunal recurre a esta alternativa procesal cuando declara nula una ley y reconoce que es difícilmente tolerable una situación jurídica sin ley; se necesita en consecuencia una regulación legal hasta que el legislador dicte la nueva norma.

El legislador podría aprovechar esta oportunidad para hacer modificaciones, en tanto las regulaciones transitorias son limitadas en el tiempo. En los hechos es frecuente que el legislador recoja la argumentación jurídica del tribunal, expresada en la regulación transitoria, y la integre en la ley, porque supone que así obra sobreseguro.

Menos frecuentes son los casos en los cuales el tribunal concibe una norma que entrará en vigencia recién cuando el legislador haya dejado transcurrir el plazo 
fijado por el tribunal para presentar una nueva norma. Esta legislación de reemplazo no se puede justificar de ninguna forma en relación con las competencias.

8. Algo similar se puede observar en la dictación de medidas provisionales por parte del TCF. En estos casos, el TCF regula provisionalmente la situación jurídica hasta que se decida sobre el fondo del asunto. Si se anula la ley en cuanto al fondo, el legislador tiende simplemente a asumir el criterio constitucionalmente consagrado del TCF cuando se trata de resolver la nueva norma legal.

9. Las recomendaciones y estructuras preliminares dirigidas al legislativo se pueden inferir finalmente de la estructura de fundamentos de la resolución, puesto que la fundamentación contiene los argumentos que han llevado al veredicto de inconstitucionalidad y encierra muchas veces los argumentos para una regulación conforme a la Constitución.

En este contexto también merece ser considerada la llamada obiter dicta, los considerandos del tribunal que no sirven de base al fallo, pero que son adjuntados con alguna segunda intención por el tribunal. Por sus experiencias con el poder político, el tribunal espera que sean asumidos por el legislador. Así, en el caso de materias políticas controvertidas, el grupo de promotores de una determinada norma puede invocar lo señalado por el TCF, haciendo referencia a que éste habría considerado como posible o reclamado una regulación al respecto. Resulta evidente que el tribunal interviene aquí en el proceso de formación de opinión política a favor de un partido.

\section{IV}

En el curso de sus casi 60 años de jurisdicción, el TCF ha llenado con contenidos muy concretos el ordenamiento marco original de la Ley Fundamental. El texto de la Constitución no se puede comprender sin recurrir a las respectivas resoluciones del TCF. Sólo a partir de ellas se puede deducir qué se exige de cada uno de los artículos tocadas todas las materias jurídicas imaginables; no ha habido ninguna cuestión jurídica importante que no pudiera ser una cuestión constitucional. Si bien la jurisdicción le ha señalado repetidamente al legislador que le queda un margen de conformación, la espesura de la argumentación del tribunal muchas veces dice lo contrario y confina al legislador en el papel del órgano ejecutor de las resoluciones del TCF. Con esto se despoja al legislador de su dignidad democrática. La molestia de los políticos se vierte en expresiones como las del ex jefe de gobierno, Helmut Schmidt, en sus memorias, donde plantea: "también el TCF debería aprender que los puntillosos fundamentos de sus resoluciones, que se han hecho una costumbre, tienen como resultado restricciones indeseadas"; fustiga la "manía de normar" fomentada por el TCF 
como una "epidemia psíquica que conduce al inmovilismo" y que ha terminado "extendiéndose a toda la clase política".

Se impone la pregunta en relación con qué hace el poder político para recuperar el dominio del proceso. ¿Qué contrapone el gobierno y el legislador a la pretensión de poder político del TCF? La respuesta es: nada, por lo menos nada que pudiera ser eficiente en forma duradera. El gobierno y el legislador parecen haber caído en una especie de letargo. No hay un contravirado, por el contrario, ya ni siquiera se aprovechan los espacios de conformación aún restantes. Antes de dictar una ley, el legislador parece más bien querer reasegurarse, celebra como útiles las llamadas indicaciones de navegación en las resoluciones o simplemente espera, antes de plantear una enmienda, hasta que el TCF ha decidido y, con ello, ha establecido las indicaciones conformes a la constitución, como volvió a suceder recientemente con la Ley de Impuesto a la Herencia.

Resulta evidente que tal tipo de comportamiento desafía al TCF. Se toman resoluciones sobre el fondo del asunto también donde no hay nada que resolver, ya sea porque una norma no ha sido atacada o porque la acción es procesalmente inadmisible, como un todo o en partes.

Si el gobierno y el parlamento finalmente toman una decisión presionados por los hechos, pensemos por ejemplo en las leyes de seguridad posteriores al 11 de septiembre de 2001, pueden estar seguros de que su atrevimiento no vale la pena. Sus esfuerzos por garantizar mayor protección y seguridad a la población en una era de terrorismo global se topan con una concepción de la libertad muy individual del TCF, quien responde rápidamente con su veredicto.

Resumiendo, el estado de ánimo del gobierno y el parlamento se refleja en las palabras del Ministro del Interior, Worfgang Schäuble. En una entrevista a un periódico señaló recientemente: "me parece discutible que el TCF deba decidir realmente qué tipo de instrumentos se pueden o no se pueden prever legalmente para cada tipo de delito. Es asunto del legislador decidir, para este delito puedo utilizar este instrumento y para este otro no". Y agregó: "quien quiera diseñar leyes debería preocuparse de ser elegido miembro del Parlamento". 